\title{
LATE-ONSET HYPOPARATHYROIDISM 15 YEARS AFTER THYROIDECTOMY
}

\section{INTRODUCTION}

Post-surgical hypoparathyroidism is a well known complication of total thyroidectomy. It may occur as transitory hypoparathyroidism that spontaneously recover within a few weeks/months and as permanent hypoparathyroidism needing long-term treatment.

Only few cases of hypoparathyroidism newly diagnosed many years after surgery have been reported.

We present a patient with hypoparathyroidism that became clinically evident 15 years after the thyroid surgery.

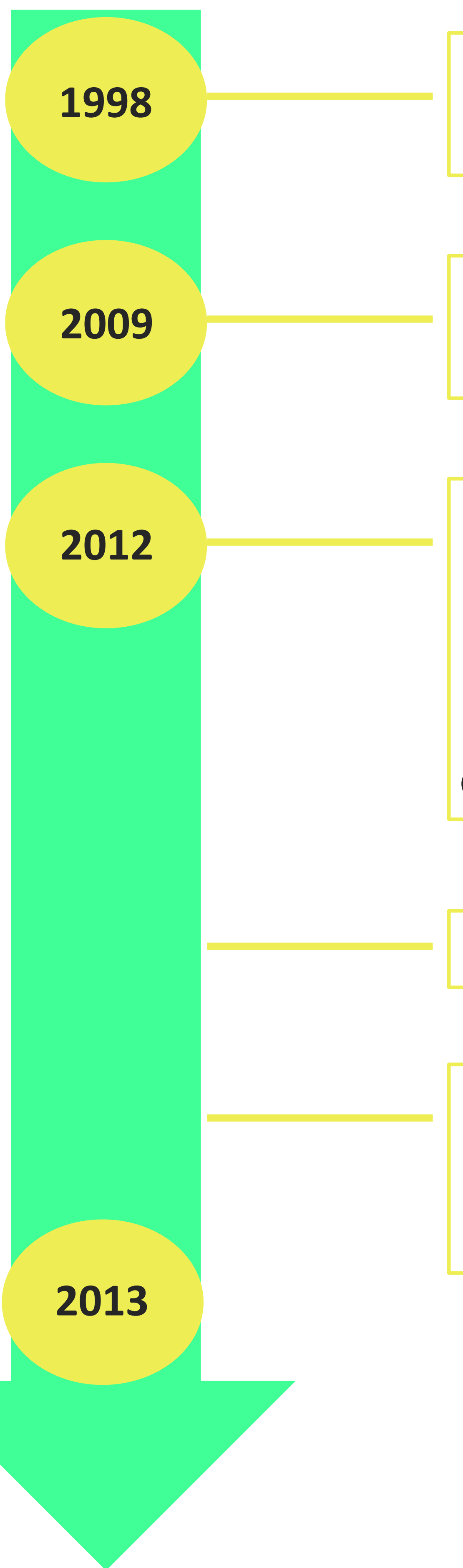

18-year-old female, submitted to total thyroidectomy for papillary thyroid carcinoma (pT2N1bM0) at another institution.

She might have done radioiodine ablation therapy (we do not know the dose neither post-therapy scan).

She was referred to Endocrinology consultation in September/09 for follow-up.

No evidence of recurrence, so far, and the patient remained clinically asymptomatic.

In March/12 she was observed in the Emergency Department due to complaints of hand paresthesias and carpal spasm.

Severe hypocalcaemia was diagnosed:

$\mathrm{Ca}=5,4 \mathrm{mg} / \mathrm{dL}[8,8 ; 10,6], \mathrm{Ca}^{2+}=0,68 \mathrm{mg} / \mathrm{dL}[1,15 ; 1,35]$

She was treated with i.v. calcium gluconate and after resolution of signs and symptoms was discharged on calcitriol, calcium carbonate and cholecalciferol therapy.

Due to constipation, she abandoned by her own initiative calcitriol a month later.

In May/12 the analytical study of calcium metabolism revealed postsurgical hypoparathyroidism, normal renal function and vitamin $D$ $\mathrm{PTH}=10.2 \mathrm{pg} / \mathrm{mL}[10 ; 65], \mathrm{Ca}=4.1 \mathrm{mEq} / \mathrm{L}[4.2-5.1], \mathrm{Ca}^{2+}=2.04 \mathrm{mmol} / \mathrm{L}[2.26-2.64], \mathrm{PO} 4^{3-}=4.6 \mathrm{mg} / \mathrm{dL}[2.7-4.5], \mathrm{Mg}^{2+}=1.50 \mathrm{mEq} / \mathrm{L}[1.55 ; 2.05]$

The patient is now asymptomatic on supplementation with calcitriol, calcium and cholecalciferol.

\section{CONCLUSION}

Late-onset hypoparathyroidism appearing years after total thyroidectomy is a rare condition.

Symptoms of hypocalcemia may be latent and subtle (such as weakness, tiredness, irritability and depression) and thus attributed to other diseases.

Although hypocalcemia typically occur after surgery, progressive atrophy of the parathyroid glands, leading to its insufficiency years after thyroid surgery, may result in a late latent hypocalcemia.

Although we lack data on radioactive iodine $\left({ }^{131}\right)$ therapy and she is not able to ensure us that information, it is another possible factor contributing to late hypoparathyroidism.

1) Hafsah Al-Azem et al, Hypoparathyroidism, Endocrinology \& Metabolism, volume 26 (4), 2012, 517-522

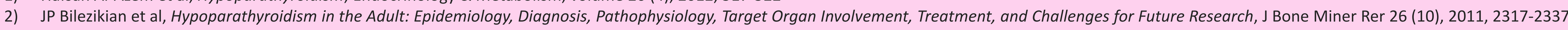

3) R Kelly and H Taggart, Hypoparathyroidism--presenting 40 years after thyroid surgery, UMJ 67(1) 1998, 63-64

4) R J Bellamy, Unrecognized hypocalcaemia diagnosed 36 years after thyroidectomy, J R Soc Med, 88, 1995, 690-691 